\title{
Measuring Energy Efficiency Practices in Mature Data Center: A Maturity Model Approach
}

\author{
Edward Curry ${ }^{1}$, Gerard Conway ${ }^{2}$, Brian Donnellan ${ }^{3}$, Charles Sheridan ${ }^{4}$, and \\ Keith Ellis ${ }^{4}$
}

\begin{abstract}
Power usage within a Data Center (DC) goes beyond the direct power needs of servers to include networking, cooling, lighting and facilities management. Data centers range from closet-sized operations, drawing a few kilowatts $(\mathrm{kW})$, to mega-sized facilities, consuming tens of megawatts (MWs). In almost all cases, independent of size there exists significant potential to improve both the economic and environmental bottom line of data centers by improve their energy efficiency, however a number of challenges exist. This paper describes the resulting maturity model, which offers a comprehensive value-based method for organizing, evaluating, planning, and improving the energy efficiency of mature data centers. The development process for the maturity model is discussed, detailing the role of design science in its definition.
\end{abstract}

\section{Introduction}

It is estimated that Information and Communication Technology (ICT) is responsible for at least $2 \%$ of global greenhouse gas (GHG) emissions with Data Centers (DC)'s accounting for $14 \%$ of the ICT footprint [1]. According to McKinsey \& Co. [2] the world's 44 million servers consume $0.5 \%$ of all electricity and produce $0.2 \%$ of carbon dioxide emissions, or 80 megatons a year. The emissions generated for all the DC's globally are approaching the emissions levels of entire countries like Argentina or the Netherlands that are ranked $142^{\text {nd }}$ and $146^{\text {th }}$ respectively. Given a business as usual scenario greenhouse gas emissions from DC are projected to more than double from 2007 levels by 2020 [1].

The efficient operation of a data center requires a diverse range of knowledge and skills from a large ecosystem of stakeholders. A Data Center (DC) requires expertise from engineering (including electrical, civil, mechanical, software and

\footnotetext{
${ }^{1}$ Digital Enterprise Research Institute National University of Ireland, Galway

${ }^{2}$ Gerard Conway $(\bowtie)$

Innovation Value Institute National University of Ireland, Maynooth

email: gerard.conway@nuim.ie

${ }^{3}$ Innovation Value Institute National University of Ireland, Maynooth

${ }^{4}$ Intel Labs Europe, Intel Corporation
} 
electronic) to accountancy to systems management. Working in a DC may require knowledge of, the laws of thermodynamics and OpEx charge-back accounting principles in the same day. To address this issue, a consortium of leading organizations from industry, the nonprofit sector, and academia has developed and tested a framework for systematically improving Energy Efficiency (EE) capabilities within mature DCs.

The Innovation Value Institute (IVI; http://ivi.nuim.ie) consortium used an open-innovation model of collaboration; engaging academia and industry in scholarly work to create a data center energy efficiency assessment. It offers a comprehensive value-based model for organizing, evaluating, planning, and managing DC capabilities for energy efficiency, and it fits within the IVI's ITCapability Maturity Framework (IT-CMF). The objective of the assessment is to provide a high-level assessment of maturity for IT managers with responsibility for DC operations. This paper describes the Data Center Energy Efficiency maturity model.

\section{Data Center Entergy Consumption}

With power densities of more than 100 times that of a typical office building, energy use is a central issue for DCs. The US Environmental Protection Agency estimates that servers and DCs are responsible for up to $1.5 \%$ of the total US electricity consumption [3] or roughly .5\% of US GHG emissions for 2007. Massive growth in the volumes of computing equipment, and the associated growth in areas such as cooling equipment has lead to increased energy usage and power densities within data centers. If growth continues in line with demand, the world will be using 122 million servers in 2020. Trends toward cloud computing have the potential to further increase the demand for DC-based computing services.

Power usage within a DC goes beyond the direct power needs of servers to include networking, cooling lighting and facilities management with power draw for data centers ranging from a few $\mathrm{kWs}$ for a rack of servers to several tens of MWs for large facilities. While the exact breakdown of power usage will vary between individual DCs, Figure 1 illustrates the examination of one DC where up to $88.8 \%$ of the power consumed by the DC was not used on computation; for every 100 watts supplied to the data center only 11.2 watts were used for computation [3].

Air conditioners, power converters and power transmission can use almost half of the electricity in the datacenter, the IDC estimates that DC energy costs will be higher than equipment costs by 2015 [4]. The cost of operating a data center goes beyond just the economic bottom line; there is also an environmental cost. By 2020 , the net footprint for data centers is predicted to be $259 \mathrm{MtCO} 2 \mathrm{e}$ [1]. There is significant potential to improve both the economic and environmental bottom line of data centers by improve their energy efficiency, however a number of challenges exist. 


\section{Energy Efficiency within Mature Data Centers}

Data centers are complex eco-systems that interconnect elements of the ICT, electrical and mechanical fields of engineering. Energy efficient data center operations require a holistic approach to both IT and facilities energy management. Organizations face many challenges in developing and driving their overall DC EE strategies and programs: the complexity of the subject and its rapid evolution, the lack of DC EE subject-matter expertise, the lack of relevant instrumentation and information within mature DCs, the need for new metrics and measures and the need for multiple stakeholder engagement and agreement (IT, facilities, business users), With electricity costs the dominant operating expense of a DC it is vital to maximize the efficiency to reduce both the environmental and economic cost. DC and IT leaders frequently can't find satisfactory answers to questions such as: What is the utilization of the DC? Is the infrastructure provisioned appropriate for the business requirements? How energy efficient is the DC? Where are the inefficiencies? Are there clear measurable goals and objectives for DC EE? What more could be done to contribute to DC EE goals? What is the roadmap for DC EE improvements?

\section{The Need for a Data Center Energy Efficiency Maturity Model}

Maturity models are tools that have been used to improve many capabilities within organizations, from Business Process Management (BPM) [5] to Software Engineering (CMMI) [6]. Typically, these models consist of a set of levels that describe how well the behaviors, practices, and processes of an organization can reliably produce required outcomes. They can have multiple uses within an organization, from defining a place to start, to providing a foundation to build a common language and shared vision, to defining priorities and roadmaps. If defined by a community the model can capture the collective knowledge of the community's prior experiences. A maturity model could also be used as an assessment tool and benchmark for the comparative assessments of the capabilities of different organizations.

Maturity models have also been developed to support the management of IT organizations. The Innovation Value Institute (IVI; http://ivi.nuim.ie), a consortium of leading organizations from industry (including, Microsoft, Intel, SAP, Chevron, Cisco, Boston Consultancy Group, Ernst \& Young, and Fujitsu) the nonprofits sector, and academia, have developed the IT-Capability Maturity Framework (IT-CMF) [7]. The IT-CMF provides a high-level process capability maturity framework for managing the IT function within an organization to deliver greater value from IT by assessing and improving a broad range of management practices. The framework identifies critical IT capabilities and defines maturity models for each process. A core function of the IT-CMF is to act as an assessment tool and a management system. 
There is a need to improve the behaviors, practices and processes within data centers to deliver greater energy efficiency. To address the issue, the IVI consortium has extended the IT-CMF with a maturity model for systematically assessing and improving DC capabilities for energy efficiency.

\section{Design Methodology}

The IVI consortium engages in an open-innovation model of collaboration, engaging academia and industry in scholarly work to create the DE EE Maturity Model. As maturity addresses a number of different interrelated concerns including strategy, information management, facilities managements, the approach taken adheres to design science guidelines. The development of the model was undertaken using a design process [8] with defined review stages and development activities based on the design science research guidelines advocated by Hevner et al. [9].

During the design process, researchers participate together with practitioners within research teams to research and develop the model. The research team interviewed multiple DC stakeholders to capture the views of key domain experts and to understand current practice and barriers to improving DC EE. The team widely consulted the relevant literature, both industrial and academic, on DC EE. Industrial best practices including the EU code of conduct for DE EE and the work of the Green Grid on metrics were incorporated. Once the model was developed it was piloted within a number of DCs with learning and feedback incorporated into subsequent versions. The core of the resulting maturity model for DC EE provides a management system with associated improvement roadmaps that guide senior IT and business management in selecting strategies to continuously improve, develop, and manage the DC capability for EE.

\section{Maturity Model for Energy Efficiency in Mature Data Center}

The Data Center Energy Efficiency model offers a comprehensive value-based model for organizing, evaluating, planning, and managing DC EE capabilities. The model fits within the IT-Capability Maturity Framework (IT-CMF) [7] and is aligned with the broader Sustainable ICT critical process maturity model [10].

The DC EE assessment methodology determines how different DC capabilities are contributing to energy efficiency goals and objectives. This gap analysis between what energy efficiency targets are, and what they are actually achieving, positions the model as a management tool for aligning relevant capabilities with EE objectives [11]. The model focuses on the execution of four key actions to improve the management $\mathrm{EE}$ in the DC: define the goals and objectives for the DC EE program, understand the current DC capability maturity level, systematically develop and manage the DC capability building blocks, assess and manage DC 
progress over time. In the remainder of this section we outline the main components of the model in more detail and discuss the assessment approach.

\subsection{Capability Building Blocks}

The maturity model consists of seven capability building blocks (see Table I.) across the following three categories: Management, including the organizational structure, policy, and metering of the DC; Operations, which includes the efficient management of existing and new IT equipment and services; Building, which covers how air management, cooling and power infrastructure are managed to increase energy efficiency.

Table 1 Capability Building Blocks of Energy Efficicent Data Centers

\begin{tabular}{lll}
\hline Category & Capability & Description \\
\hline Mgmt. & $\begin{array}{l}\text { Organizational } \\
\text { Structure }\end{array}$ & $\begin{array}{l}\text { How the data center and its energy efficiency is managed, } \\
\text { who is responsible for running the DC and how integrated are: } \\
\text { IT, Facilities, and the Business } \\
\text { The policies in place for energy efficiency within the DC and } \\
\text { how they are aligned across the enterprise. }\end{array}$ \\
& $\begin{array}{l}\text { Manageability } \\
\text { and Metering }\end{array}$ & $\begin{array}{l}\text { The metering use by IT and facilities to improve understand- } \\
\text { ing and manageability of energy usage. }\end{array}$ \\
Operations & $\begin{array}{l}\text { IT Infrastructure } \\
\text { and Services }\end{array}$ & $\begin{array}{l}\text { The management of IT equipment and services to ensure en- } \\
\text { ergy efficiency. }\end{array}$ \\
& $\begin{array}{l}\text { Internal Air } \\
\text { and Cooling }\end{array}$ & The internal air management techniques employed. \\
& Cooling Plant & The design and management of the cooling system. \\
& $\begin{array}{l}\text { Power } \\
\text { Infrastructure }\end{array}$ & $\begin{array}{l}\text { The management of power generation, conditioning and de- } \\
\text { livery systems to maximize energy efficiency. }\end{array}$
\end{tabular}

\subsection{Assessment Approach}

The assessment begins with an online survey of DC stakeholders to understand their individual assessments of the maturity and importance of these capabilities. The survey takes no more than 30 minutes to complete. Typically, a range of individuals who are involved in, or accountable for, EE for the DC complete the survey. A series of targeted interviews with key stakeholders augments the survey to understand key business priorities and energy efficiency drivers, successes achieved, and initiatives taken or planned. Interviews last between 60 and 90 minutes; they are used to support the survey data. In addition to helping organizations understand their current maturity level, the initial assessment provides insight into the value placed on each capability, which will undoubtedly vary according to each organization's strategy and objectives. The assessment also 
provides valuable insight into the similarities and differences in how key stakeholders view both the importance and maturity of individual capabilities, as well as the overall vision for success. Understanding the current levels of maturity and strategic importance lets an organization quickly identify gaps in capabilities. This is the foundation for developing a meaningful action plan [12].

\subsection{Assessing and Managing Progress}

With the initial assessment complete, organizations will have a clear view of current capability and key areas for action and improvement. However, to further develop the capability, the organization should assess and manage progress over time by using the assessment results to develop a roadmap and action plan and add a yearly/half-yearly follow-up assessment to the overall DC energy efficiency management process to measure over time both progress and the value delivered from improving energy efficiency. Agreeing on stakeholder ownership for each priority area is critical to developing both short-term and long-term action plans for improvement. The assessment results can be used to prioritize the opportunities for quick wins - that is, those capabilities that have smaller gaps between current and desired maturity.

\subsection{Maturity Levels}

To get an understanding of each maturity level, the following section outlines what is required at each level and the characteristic of each capability. It is important to note that a DC can be at different levels of maturity for each capability.

The first maturity level is Initial and it is characterized by the absence of any formal EE practices or processes within IT or it management structure.

Table 2 Level 1: Initial Data Center Energy Efficiency

\begin{tabular}{ll}
\hline Capability & Maturity \\
\hline $\begin{array}{l}\text { Organizational } \\
\text { Structure }\end{array}$ & No formal organizational structure expected at this level. \\
Policy & No formal EE policies in place. \\
$\begin{array}{ll}\text { Manageability } \\
\text { and Metering }\end{array}$ & $\begin{array}{l}\text { IT has no specific energy related metrics or metering capability in place. Facili- } \\
\text { ties have limited building level metering. Shared metering systems are used that } \\
\text { require manual readings for different support infrastructure. No visualization }\end{array}$ \\
& $\begin{array}{l}\text { medium is used to improve manageability of energy data. } \\
\begin{array}{l}\text { IT Infrastructure Ad-hoc. } \\
\text { and Services }\end{array}\end{array}$
\end{tabular}




\begin{abstract}
Internal Air Ad-hoc design and operation. Typically peripheral/perimeter air-cooling is utiand Cooling lized within the DC. Air supply temperatures are significantly cooler than needed $\left(\sim 13-15^{\circ} \mathrm{C}\right)$ to compensate for a high level of air mixing. No air management techniques are in place. In chilled water DCs Leaving Water Temperature (LWT) at the cooling plant is lower than needed $\left(\sim 4-5^{\circ} \mathrm{C}\right)$.

Cooling Plant Cooling is supplied based on resilience. Energy conservation is not a major consideration. DC predominantly relies on refrigeration cycle \& Co-efficient Of Performance (COP) is typically $<3$. Cooling infrastructure is oversized relative to current IT load. Configuration is static (i.e. pumps at fixed speed)
\end{abstract}

The Basic level of maturity is the start of some formal management structure with a base level of understanding of the impact of EE within the DC.

Table 3 Level 2: Basic Data Center Energy Efficiency

\begin{tabular}{|c|c|}
\hline Capability & Maturity \\
\hline $\begin{array}{l}\text { Organizational } \\
\text { Structure }\end{array}$ & $\begin{array}{l}\text { EE is considered by IT \& facilities but with a siloed or disjointed approach to } \\
\text { energy management. }\end{array}$ \\
\hline Policy & $\begin{array}{l}\text { IT policies have limited consideration for decommissioning, consolidation, re- } \\
\text { fresh, efficient storage allocation, and virtualization. Facility policy position EE } \\
\text { as an operational decision criterion. Both IT \& Facilities equipment purchase } \\
\text { and upgrade decisions have energy related criterion. Policy creation is siloed. }\end{array}$ \\
\hline $\begin{array}{l}\text { Manageability } \\
\text { and Metering }\end{array}$ & $\begin{array}{l}\text { IT understands IT electrical load and can meter at the UPS level. Some larger } \\
\text { facilities infrastructure has individual metering installed such as the chiller } \\
\text { units. Static power capping and other fixed strategies are in place. A useable } \\
\text { granularity of data is in place i.e. ever hour or better. Basic information systems } \\
\text { exist for energy data analysis and decision support. Metrics such as kWh con- } \\
\text { sumed and/or PUE / DCiE are defined and are used to dive effective decisions. } \\
\text { Basic measurements in place for air temp, Humidity (HUM), \& pressure. }\end{array}$ \\
\hline $\begin{array}{l}\text { IT Infrastructur } \\
\text { and Services }\end{array}$ & $\begin{array}{l}\text { Defined IT landing procedures in place that considers EE. Auditing \& decom- } \\
\text { missioning of unused or un-valued equipment. Appropriate storage allocation } \\
\text { and some level of server consolidation in place. Existing server energy saving } \\
\text { features are utilized. Processor P state energy saving modes are enabled. }\end{array}$ \\
\hline $\begin{array}{l}\text { Internal Air } \\
\text { and Cooling }\end{array}$ & $\begin{array}{l}\text { IT equipment inlet supply temperatures lower than the low end of the ASHRAE } \\
\text { recommendations due to air mixing (at time of writing } \sim 16-18^{\circ} \mathrm{C} \text { ). In chilled } \\
\text { water DCs LWT is slightly higher than L1 due to supply air temp increase. IT } \\
\text { equipment is oriented in a cold aisle hot aisle configuration. Blanking panels } \\
\text { within racks are utilized and gaps in floor are sealed. HUM utilizes a fixed set } \\
\text { point. Auditing for improvement opportunities are conducted such as inlet temp. }\end{array}$ \\
\hline Cooling Plant & $\begin{array}{l}\text { Refrigeration infrastructure is appropriately sized or strategies are in place to } \\
\text { align cooling capacity \& demand. Typically COP is } \sim 3-4 \text {. But refrigeration is } \\
\text { still predominately required. Limited economization utilized. }\end{array}$ \\
\hline $\begin{array}{l}\text { Power } \\
\text { Infrastructure }\end{array}$ & $\begin{array}{l}\text { UPS is more effectively sized or strategies employed to appropriately align de- } \\
\text { mand and capacity relative to existing IT load. Efficiency is typically } \sim 90 \% \text { at } \\
50 \% \text { load or above. }\end{array}$ \\
\hline
\end{tabular}

The Intermediate level of maturity shows that all of the major components are in place for the efficient management of the EE within the data center. 
Table 4 Level 3: Intermediate Data Center Energy Efficiency

\begin{tabular}{|c|c|}
\hline Capability & Maturity \\
\hline $\begin{array}{l}\text { Organi } \\
\text { Structu }\end{array}$ & $\begin{array}{l}\text { EE is inherent in policies and the management of the DC and takes account of } \\
\text { the interrelationship of IT \& Facilities. Both disciplines share knowledge open- } \\
\text { ly and work together to improve EE of the business offering. }\end{array}$ \\
\hline Policy & $\begin{array}{l}\text { IT server landing policies take account of facility cooling requirements. Cable } \\
\text { and air management best practice are defined. Policy moves towards increased } \\
\text { virtualization. There is an efficient and effective customer requirement program } \\
\text { in place that matches service to needs. Facilities have defined improvement } \\
\text { roadmap that targets sustainable operations. There is a resilience review poli- } \\
\text { cy/audit. External best practices are systematically reviewed and internalized. } \\
\text { Best practice policies exist for new DC design and build. }\end{array}$ \\
\hline $\begin{array}{l}\text { Manageability } \\
\text { and Metering }\end{array}$ & $\begin{array}{l}\text { IT have granular understanding of IT electrical load through metering at the } \\
\text { power distribution unit / board level. Facilities have an increased level of sup- } \\
\text { port infrastructure metered. Granularity of metering is } 15 \text { minutes or better. DC } \\
\text { information systems combine the IT \& facilities energy data with dashboards } \\
\text { supporting decision-making. Environmental data both internal \& externally is } \\
\text { integrated into dashboard (i.e. weather data affects on air-cooled chillers). Basic } \\
\text { remote intelligent control of IT \& facilities infrastructure is available. }\end{array}$ \\
\hline $\begin{array}{l}\text { IT Infrastructure } \\
\text { and Services }\end{array}$ & $\begin{array}{l}\text { Comprehensive consolidation program in place. } \mathrm{DC} \text { has begun to move some } \\
\text { legacy services to virtualized environments. IT services are moving towards de- } \\
\text { livering valued performance per watt. }\end{array}$ \\
\hline $\begin{array}{l}\text { Internal Air } \\
\text { and Cooling }\end{array}$ & $\begin{array}{l}\text { Air inlet supply temperature at lower end of the ASHRAE recommendations (at } \\
\text { time of writing } \sim 20-21{ }^{\circ} \mathrm{C} \text { ). In addition to blanking/sealing an optimized diffus- } \\
\text { er layout has been implemented, ideally based on CFM or similar study. Row } \\
\text { based cooling utilized or perimeter. Additional air barriers are used to minimize } \\
\text { air mixing. CRAC/CRAH units are powered down or throttled back to match } \\
\text { air capacity to heat load to save on motor fan consumption. HUM uses a tight } \\
\text { floating set point range. LWT is increased in line with the server supply temp. }\end{array}$ \\
\hline Cooling Plant & $\begin{array}{l}\text { COP is typically } \sim 4-6 \text {. Both standalone and systemic efficiency are considered. } \\
\text { Pumps have Variable Frequency Drives (VFDs). Cooling coils have an econo- } \\
\text { mization mode that turns off refrigeration cycle if outside conditions permit. } \\
\text { Partial wetside/airside economization is increasingly utilized, } \sim 50 \% \text { of the year. }\end{array}$ \\
\hline $\begin{array}{l}\text { Power } \\
\text { Infrastructure }\end{array}$ & $\begin{array}{l}\text { UPS is correctly sized. The UPS is typically } \sim 93 \% \text { efficient or above at } 50 \% \\
\text { load. There is an optimal number of PDUs. }\end{array}$ \\
\hline
\end{tabular}

The 4th level of maturity is Advanced which is characterized by a consistent and coordinated approach that is above the industrial average and where there is continuous improvement.

Table 5 Level 4: Advanced Data Center Energy Efficiency

\begin{tabular}{ll}
\hline Capability & Maturity \\
\hline $\begin{array}{l}\text { Organizational } \\
\text { Structure }\end{array}$ & $\begin{array}{l}\text { Holistic management approach that understands the symbiotic relationships be- } \\
\text { tween IT \& Facilities, and leverages heuristics in both domains. Operational de- } \\
\text { cisions balance sustainability, resilience, and business needs. }\end{array}$ \\
\hline
\end{tabular}


Policy Policies reflect a harmonized process based approach. Best practices are disseminated within the enterprise. IT has a default virtualization and exception justification policy. EE is a criterion in terms of service offerings and purchases. For existing facilities CapEx funding programs/policy for upgrading existing infrastructure are in place. EE begins at the software level to combat code bloating and wasteful service provisioning. The DC function engages and influences with regard to external best practice. Best practice eco-design policies including climate and location in decisions for new-build or re-engineering of DCs. Built environment best practice are incorporated with relevant 3rd party accreditation.

Manageability IT has rack \& server level consumption data together with environmental data and Metering like temperature and HUM. Facilities infrastructure is completely metered from an electrical standpoint. Environment data internally \& externally is totally integrated along with the full electrical consumption data. Any water consumption is assessed and is considered as part of sustainability goals, metrics such Water Usage Effectiveness (WUE) are considered. A pervasive level of dynamic control is in place that leverages virtualized environments to spin up/down servers/services. Facilities are dynamically matched to IT load with VFD, pump and motor, intelligent control logic utilized.

IT Infrastructure Virtualization is the default practice in terms of server and storage service proand Services vision. IT moves toward machine readable Service Level Agreements (SLAs).

Internal Air Air inlet supply temperature at middle of ASHRAE recommendations (at time and Cooling of writing $\sim 22-24^{\circ} \mathrm{C}$ ). Full air segregation in place. Cold aisle/ hot aisle/ chimney cabinets/in-rack cooling utilized. CRAC/CRAH units have VFDs and controlled based on dynamic metering. DC utilizes a widened floating set point range for HUM. LWT is $\sim 10-12{ }^{\circ} \mathrm{C}$. Wetside/airside economization is utilized.

Cooling Plant Where refrigeration is utilized all fans \& pumps have VFDs. COP is typically $\sim 6$ or greater and normal operation is economization mode $\sim 75 \%$ of the year. Wetside economization / evaporation direct free air-cooling is utilized.

Power UPS has a $\sim 94 / 95 \%$ or better efficiency at $\sim 50 \%$ load. UPS is modular. The Infrastructure UPS is correctly sized to the data center load. Redundancy is appropriate for the criticality of the load. Rack PDU's are efficient with less than 3\% loss. Noncritical load maybe removed off the UPS. Renewable energy resources like solar are considered for lighting systems or heat blocks for back-up generators, etc.

The final and highest level of maturity is Optimizing where policies, procedures and standards for EE are set at the highest possible level.

Table 6 Level 5: Optimizing Data Center Energy Efficiency

\begin{tabular}{ll}
\hline Capability & Maturity \\
\hline $\begin{array}{l}\text { Organizational } \\
\text { Structure }\end{array}$ & A team led by a senior executive has responsibility for EE across the enterprise. \\
Policy & Sustainability is an inherent value and capability within the enterprise. \\
& $\begin{array}{l}\text { Energy efficiency policy is a continuum from the enterprise-level to the soft- } \\
\text { ware code level and everything in-between. Policies influence beyond the en- } \\
\text { terprise boundaries requiring vendors and suppliers to incorporate sustainable } \\
\text { practices. DC function actively engages in industry bodies and forums regard- } \\
\text { ing best practice and influences EE throughout the enterprise supply-chain. }\end{array}$ \\
\hline
\end{tabular}




\begin{abstract}
Manageability IT can measure electrical load at service-level, matching consumption to useful and Metering work done. Facilities infrastructure and IT infrastructure is completed metered and optimized automation is in place. Environmental data is completely integrated and all cause and effect relationships are understood. Management dashboards are highly effective decision tools that incorporate energy, resilience, and business variables. Metering and control capabilities extend beyond the DC with real-time integration with other building infrastructure or smart grid infrastructure in terms of energy management, energy re-use, trading, etc.

IT Infrastructure DC environment is almost exclusively virtualized. Dynamic service manageand Services ment allows transferable workloads. Power usage is matched to valued workload. The enterprise can move service between its data center estate. Cloud based services and energy service level agreements are in place.

Internal Air Inlet temperature is run at the top end of ASHARE recommendations or higher and Cooling (at time of writing $\sim 25-27^{\circ} \mathrm{C}$ ). An optimal floating HUM set point is used. DC normal operational mode is 'free-cooling' economization.

Cooling Plant Evaporative cooling (Wetside economization), or direct free air-cooling is utilized in climates that permit. Direct touch cooling utilized. Heat recovery systems utilized where appropriate; redundancy has little effect on EE.

Power UPS is modular and the most efficient for the given DC, $\sim 96 \%$ efficient at Infrastructure $\quad \sim 40 \%$ load or less. Flywheel may be used for storage, if appropriate. Appropriate non-critical applications are on mains-only. Renewable energy sources are utilized with onsite self-generation where possible. Natural or LED lighting used. A move to direct current design is considered.
\end{abstract}

\title{
References
}

1. Webb M (2008) SMART 2020: Enabling the low carbon economy in the information age, The Climate Group London.

2. Forrest W, Kaplan J M (2008) Data centers: How to cut carbon emissions and costs, McKinsey on Business Technology, vol. 14, no. 6.

3. S. ENERGY (2007) Report to Congress on Server and Data Center Energy Efficiency Public Law 109-431," Environmental Protection, vol. 109, p. 431.

4. Martinez N, Bahloul K (2008) Green IT Barometer European Organisations and the Business Imperatives of Deploying a Green and Sustainable IT Strategy. IDC.

5. Rosemann M, De Bruin T (2005) Towards a Business Process Management Maturity Model, in 13th European Conference on Information Systems, vol. 53, no. 1, pp. 521-532.

6. Paulk M C, Curtis B, Chrissis M B, Weber CV (1993) The Capability Maturity Model for Software, Software engineering project management, vol. 10, pp. 1-26.

7. Curley M, (2004) Managing Information Technology for Business Value: Practical Strategies for IT and Business Managers. Intel Press.

8. Donnellan B, Helfert M, (2010) The IT-CMF: A Practical Application of Design Science, in Lecture Notes in Computer Science, Vol. 6105, DESRIST 2010.

9. Hevner A R, March S T, Park J, Ram S (2004) Design Science in Information Systems Research, MIS Quarterly, vol. 28, no. 1, pp. 75-105.

10. Donnellan B, Sheridan C, Curry E (2011) A Capability Maturity Framework for Sustainable Information and Communication Technology, IT Professional, vol. 13, no. 1, pp. 33-40.

11. Curry E, Guyon B, Sheridan C, Donnellan B (2012) Developing an Sustainable IT Capability: Lessons From Intel's Journey. MIS Quarterly Executive. Vol.11, no. 2, pp.61-74.

12. Curry E, Donnellan B. (2012) Understanding the Maturity of Sustainable ICT. In: Brocke J vom, Seidel S, Recker J, editors. Green Business Process Management - Towards the Sustainable Enterprise. Springer p. 203-216. 